\title{
Evaluation of Exposures in a Steel Coil Pickling Plant
}

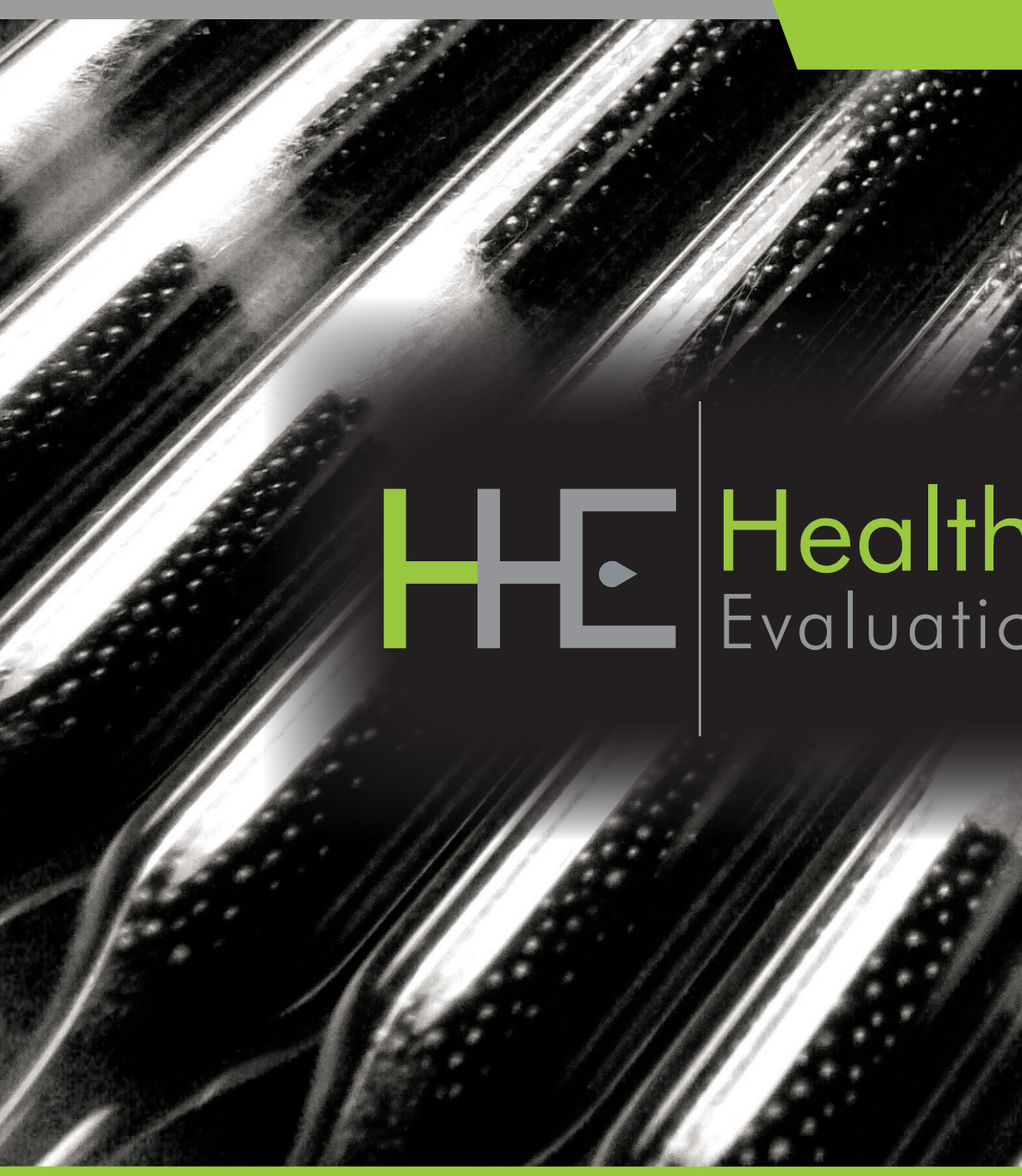

HHE Report No. 2017-0022-3311 April 2018
Jessica F. Li, MSPH Marie A. de Perio, MD 


\section{Contents}

Highlights.

Abbreviations ...................................... iii

Introduction ............................................ 1

Methods ............................................... 3

Results ............................................... 5

Discussion ........................................ 12

Conclusions....................................... 15

Recommendations.............................. 15

Appendix A ...................................... 17

References........................................ 22

Acknowledgements............................ 25

The employer is required to post a copy of this report for 30 days at or near the workplace(s) of affected employees. The employer must take steps to ensure that the posted report is not altered, defaced, or covered by other material.

The cover photo is a close-up image of sorbent tubes, which are used by the HHE Program to measure airborne exposures. This photo is an artistic representation that may not be related to this Health Hazard Evaluation. Photo by NIOSH. 


\section{Highlights of this Evaluation}

The Health Hazard Evaluation Program received a request from an employer representative at a steel pickling plant. The employer was concerned about employee exposures to electrostatically-applied oil, diesel exhaust, and airborne particulate in and around the steel coil pickling line. Additionally, we learned about concerns about hydrochloric acid and noise exposures on the pickling line. We visited the plant in March 2017.

\section{What We Did}

- We collected full-shift personal air samples for oil mist, diethylene glycol monobutyl ether (a chemical in the oil used for pickling), hydrochloric acid, and elemental carbon.

- We collected full-shift area air samples for oil mist, hydrochloric acid, and elemental carbon.

- We measured full-shift personal noise exposures on exit laborers and an exit operator.

- We measured area noise in the pickling line entry area and in two crane cabs.

- We took short-duration sound level measurements near noisy equipment.

- We checked the ventilation on the pickling line and in the quality wet lab.

- We reviewed injury and illness logs, respiratory protection and other personal protective equipment policy documents, and audiometry records.

- We held con idential medical interviews with all employees working on all three shifts.

We evaluated exposures to electrostatically-applied oil mist, hydrochloric acid, diesel exhaust, and noise, in a steel pickling plant. We found a high prevalence of reported workrelated irritant symptoms among production employees. We found higher diesel exhaust levels in crane cabs and overexposures to noise on the pickling line. We recommended engineering controls and the use of hearing protection to reduce workplace exposures.

\section{What We Found}

- Many employees reported symptoms, including cough, sore throat, and nasal congestion, that improved away from work.

- Air sampling did not find any overexposures to oil mist or diethylene glycol monobutyl ether.

- Elemental carbon levels were higher in the crane cabs than outside of the plant.

- One exit operator and one exit laborer were overexposed to noise.

- Area noise measurements collected in the entry area were high, but full-shift personal noise exposures were not measured.

\section{What the Employer Can Do}

- Provide ventilated enclosures for the crane cabs. 
- Discuss with the manufacturer of the electrostatic oiler ways to reduce oil mist from escaping.

- Conduct personal noise sampling on pickling line entry area and quality assurance employees.

- Consult with equipment makers when buying new equipment or replacing equipment to get equipment that makes the least amount of noise.

- Encourage employees to report work-related symptoms to their supervisor and seek medical care.

\section{What Employees Can Do}

- Wear hearing protection when working on the pickling line.

- Report work-related health concerns to your supervisor.

- Seek medical care from your healthcare provider if you have symptoms to determine if they are related to exposures at work. 


\section{Abbreviations}

$\begin{array}{ll}\text { AL } & \text { Action level } \\ \text { ACGIH } & \text { American Conference of Governmental Industrial Hygienists } \\ \text { CFR } & \text { Code of Federal Regulations } \\ \text { dB } & \text { Decibels } \\ \text { dBA } & \text { Decibels, A-scale } \\ \text { DGME } & \text { Diethylene glycol monobutyl ether } \\ \text { Hz } & \text { Hertz } \\ \text { HCl } & \text { Hydrogen chloride } \\ \text { mg/m }{ }^{3} & \text { Milligrams per cubic meter } \\ \text { NIOSH } & \text { National Institute for Occupational Safety and Health } \\ \text { NIHL } & \text { Noise-induced hearing loss } \\ \text { OEL } & \text { Occupational exposure limit } \\ \text { OSHA } & \text { Occupational Safety and Health Administration } \\ \text { PEL } & \text { Permissible exposure limit } \\ \text { PPE } & \text { Personal protective equipment } \\ \text { ppm } & \text { Parts per million } \\ \text { REL } & \text { Recommended exposure limit } \\ \text { TLV® } & \text { Threshold limit value } \\ \text { TWA } & \text { Time-weighted average }\end{array}$


This page left intentionally blank 


\section{Introduction}

The Health Hazard Evaluation Program received a request from an employer representative at a steel coil pickling plant. The employer and employees were concerned about respiratory exposures to electrostatically-applied oil, diesel exhaust, and airborne particulate in the steel coil pickling line. We visited the company in March 2017. After the visit we sent letters in March 2017 to the employer and employee representatives summarizing our activities and initial recommendations. In May 2017, we also sent individual notification letters to employees who participated in personal sampling and requested their sampling results.

\section{Background and Process Description}

The pickling plant has occupied the building since 1992. At the time of our evaluation, the plant stored, cleaned, and pickled steel coils. After pickling, the coils were coated with a petroleum-based oil to inhibit rust and corrosion. Prior to 2012, the plant had a machine that rolled preservative oil onto the steel coils after pickling. In 2012, the plant began using an electrostatic oil applicator to apply a different preservative oil to the steel coils; however, this oil reportedly stained the coils and emitted an odor. In 2015, the plant changed to the oil that is currently being used in the electrostatic applicator. In 2016, after a new shipment of the oil, employees began reporting respiratory symptoms that they thought were related to the oil. Upon investigation, plant managers discovered that the oil manufacturer had increased the amount of diethylene glycol monobutyl ether (DGME), a solvent and dispersant, in the oil without notifying the plant. The plant returned the remaining oil in March 2016 and requested that the oil supplier provide a chemical analysis with each new oil shipment.

The plant operated 24 hours per day, 5 days per week on three shifts: 7 a.m. to 3 p.m., 3 p.m. to 11 p.m., and 11 p.m. to 7 a.m. When the plant was busy, employees also worked on Saturdays. Manager and customer service representatives worked in an office that was separate from the pickling line. At the time of our evaluation, there was a union presence at this plant, and the union representative participated in monthly safety meetings with the employer and employees.

Steel coils were transported to the entry area of the continuous push-pull pickling line (line) using a propane-powered transfer car. The six employees typically working on the line included one entry laborer, one entry operator, one quality assurance, two exit laborers, and one exit operator. The entry laborer prepared and positioned the steel coil at the line's entry and fed the coil into the line (Figure 1). Once in the line, the leading edge of the steel coil was cut. The coil was pre-washed with water and soap and then pickled by passing through a series of four hydrochloric acid baths of decreasing concentration from ranges of $10 \%-18 \%$ to $0.5 \%-4 \%$ hydrochloric acid solution. Employees in the quality wet lab tested the concentrations of the acid bath to ensure they were in the correct ranges. In the hydrochloric acid baths, the steel was agitated to remove any debris and rust. After the acid baths, the pickled steel was washed with hot water to remove any remaining hydrochloric acid. The steel was dried with blowers and then coated with a preservative oil using an electrostatic applicator that used voltage to uniformly disperse a fine mist of oil onto the steel. 


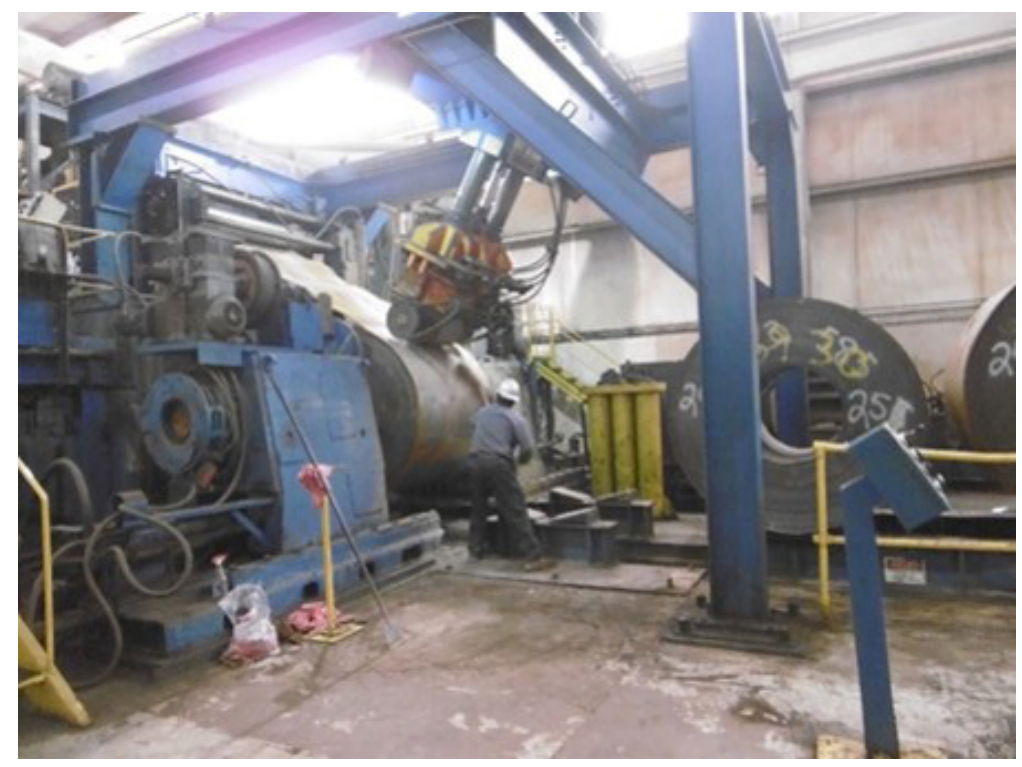

Figure 1. Entry laborer cleaning steel coil after threading steel coil through the pickling line entry. Subsequent steel coils are lined up on the right. Photo by NIOSH.

The exit operator sat closest to the electrostatic applicator and controlled the amount of the oil applied to the steel. The plant had installed a fan to blow air away from the operator's breathing zone, and an acrylic glass semi-enclosure to reduce the amount of oil that left the side of the oiler. The two exit laborers manually operated an overhead crane to remove the finished steel coils from the line to a stand. The exit laborers then used paint rollers to apply additional oil on the outside of the steel coil for extra protection before banding and labeling the steel coils with spray paint (Figure 2).

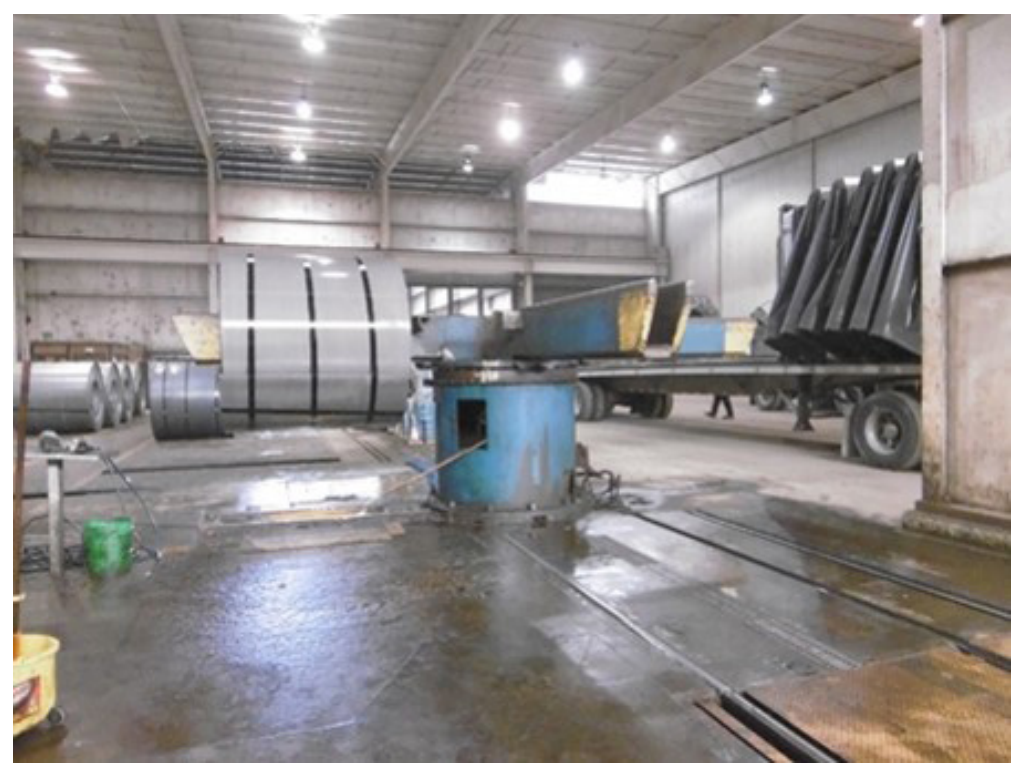

Figure 2. Finished pickled steel coil on stand after banding and application of extra outside layer of oil with a paint roller (under the coil). Photo by NIOSH. 
Crane operators in cabs used electric-powered overhead cranes to move steel coils to the line entry and from the line exit to the crane room storage area. Steel coils were transported in and out of the storage area by rail car, diesel-powered semi-trucks, and propane and dieselpowered fork trucks. The doors to the pickling plant reportedly remained open during warmer weather. During colder weather, the doors were opened and closed as needed to move coils in and out of the plant. During this evaluation, the doors remained closed. Employees mentioned that outdoor dust blew into the plant through these doors.

\section{Methods}

The objectives of our evaluation were to (1) measure employee exposures to oil mist, DGME, diesel exhaust, hydrogen chloride $(\mathrm{HCl}$, and noise at or near the steel coil pickling line; and (2) determine the prevalence of reported health symptoms and their potential relationship to work. During the site visit, we observed work practices and workplace conditions during one day shift.

\section{Document Review}

We reviewed the plant's Occupational Safety and Health Administration (OSHA) Form 300 Log of Work-Related Injuries and Illnesses covering January 1, 2012, through December 31, 2016. We reviewed safety data sheets for the electrostatically-applied oil, $\mathrm{HCl}$ solution, and steel. We also reviewed the plant's personal protective equipment (PPE) policy and the written respiratory protection program. We reviewed the plant's summary report of audiometric testing in 2016.

\section{Air Sampling}

Table 1 summarizes the personal and area air samples that were collected. When an employee left the workplace during breaks, we stopped the air sampling pumps. We restarted them upon the employee's return. 
Table 1. Air sampling*

\begin{tabular}{|c|c|c|c|}
\hline Substance & Personal air samples & Area air samples & NIOSH method $\ddagger$ \\
\hline Oil mist & $\begin{array}{l}2 \text { exit laborers; } \\
1 \text { exit operator }\end{array}$ & Near quality control station $(n=1)$ & 5026 \\
\hline $\mathrm{HCl}$ & $\begin{array}{l}2 \text { exit laborers; } \\
1 \text { exit operator }\end{array}$ & $\begin{array}{l}\text { On pickling line }(n=3) \\
\text { Crane cabs }(n=2)\end{array}$ & 1403 \\
\hline DGME & $\begin{array}{l}2 \text { exit laborers; } \\
1 \text { exit operator }\end{array}$ & None & 7907 \\
\hline Diesel exhaust $†$ & None & $\begin{array}{l}\text { Crane cabs }(n=2) ; \\
\text { Outdoors }(n=1)\end{array}$ & 5040 \\
\hline
\end{tabular}

$\mathrm{NIOSH}=$ National Institute for Occupational Safety and Health

*All air samples were collected over a full shift.

†Samples were analyzed for elemental carbon, a surrogate for diesel exhaust.

$\ddagger[\mathrm{NIOSH} 2017]$

\section{Noise}

We used Larson Davis Spark ${ }^{\mathrm{TM}}$ 706RC integrating noise dosimeters to measure timeweighted average (TWA) personal noise exposure on two exit laborers and the exit operator over one 8-hour shift. We also collected full-shift TWA area noise measurements at the pickling line entry, center crane cab, and north crane cab. The dosimeters simultaneously collected data on three different settings to compare noise measurements with the OSHA permissible exposure limit (PEL), the OSHA action level (AL), and the NIOSH recommended exposure limit (REL).

The criteria for calculating the OSHAAL include all noise exposure greater than or equal to 80 decibels, A-weighted (dBA). The criteria for calculating the OSHA PEL include all noise exposure greater than or equal to $90 \mathrm{dBA}$. The OSHAAL and the OSHA PEL use a 5-decibel (dB) exchange rate. The criteria for calculating the NIOSH REL include all noise exposure greater than or equal to $80 \mathrm{dBA}$, with a more conservative 3-dB exchange rate. When an employee left the workplace during breaks, we stopped the noise dosimeters. We re-started them upon the employee's return. We also took real-time instantaneous sound level measurements with a Larson Davis Model 831 integrating sound level meter. The instrument was set to measure instantaneous noise levels between 70 and $140 \mathrm{dBA}$ on a slow response scale.

\section{Ventilation}

We used ventilation smoke tubes to observe the airflow direction on the line and into and out of the quality wet lab.

\section{Confidential Medical Interviews}

We interviewed all 50 employees working across all three shifts during our visit. During these interviews, we discussed work history and practices and relevant medical history. We asked employees about health symptoms in the previous 3 months. We classified irritant symptoms as nasal congestion, sore throat, cough, and/or eye irritation. We considered a 
symptom to be work-related if the employee reported that the symptom was better after a few days away from work or when on vacation.

We compared the prevalence of work-related irritant symptoms among employees working primarily in the production area and those working primarily in office areas. Among the production area employees, we also compared the prevalence of work-related irritant symptoms among employees working primarily in the entry and exit areas (i.e., on the pickling line) to those primarily working in other areas of the plant. We also compared the prevalence of work-related irritant symptoms among employees working as crane operators to those working in other production areas. We calculated prevalence ratios and $95 \%$ confidence intervals.

\section{Results}

\section{Document Review}

We reviewed OSHA Logs from January 1, 2012 through December 31, 2016. Eight entries were reported over this time period and are listed in Table 2 . The entry regarding eye irritation was in an operator by the pickling line.

Table 2. OSHA Log entries at the plant, 2012-2016

\begin{tabular}{ccc}
\hline Year & $\begin{array}{c}\text { Total number } \\
\text { of entries }\end{array}$ & Number and type of injury/illness \\
\hline 2012 & 1 & 1 laceration \\
2013 & 1 & 1 chemical burn \\
2014 & 4 & 2 crushed fingers; \\
& & 1 strained shoulder; 1 eye irritation \\
2015 & 2 & 2 lacerations \\
2016 & 0 & 0 \\
\hline
\end{tabular}

We reviewed safety data sheets for the electrostatically-applied oil, the $18 \% \mathrm{HCl}$ solution, and for the coil steel. The oil was paraffinic petroleum-based and contained proprietary corrosion inhibitors and DGME. Potential health symptoms from exposure to this oil were reported on the safety data sheet to include headache and drowsiness. Recommended control measures were adequate ventilation and PPE including a respirator when adequate ventilation is not available, rubber gloves, and chemical safety goggles. The $18 \% \mathrm{HCl}$ solution (by volume in water) could react with most metals to release hydrogen gas, and heating the solution could result in gaseous $\mathrm{HCl}$ release. Health hazards from the coil steel were from metal dust or fumes, but because no steel was processed within the plant, this was not a concern.

The plant's PPE policy for production employees required safety shoes for maintenance personnel, crane operators, and entry and exit operators. Entry and exit operators were required to wear leather palmed or hot mill gloves when handling steel and/or banding. Crane operators were required to wear leather palm or Kevlar ${ }^{\circledR}$ gloves when handling steel or banding. 
Although not documented in the plant's PPE policy, managers stated that all employees were required to wear long-sleeved uniforms, safety glasses, a hard hat, and steel toed boots when on the production floor. Latex gloves and ear plugs with a noise reduction rating of $32 \mathrm{~dB}$ were also provided, but hearing protection was not described in the plant's PPE policy.

The plant's written respiratory protection program, dated March 2008, required employees to wear full-facepiece air-purifying respirators with acid vapor cartridges when working inside any enclosed area suspected to contain acid vapors, and when working in the cleanup area. Employees could voluntarily wear full-facepiece air-purifying respirators with acid vapor cartridges while working in the processing area and while cleaning or conducting any maintenance activities. The employees required to wear respirators and those who choose to voluntarily wear respirators underwent a medical evaluation. Employees required to wear respirators also received qualitative fit testing. Training was not mentioned in the written program.

A review of the plant's 2016 summary report for audiometric testing revealed that the 33 employees in the hearing conservation program were tested in 2016. Five employees had their first baseline test, and 28 employees had an annual test. One employee was reported to have a standard threshold shift as defined by OSHA. Two additional employees were found to have a decrease of more than $20 \mathrm{~dB}$ in high frequency hearing, and were referred for further medical evaluation.

\section{Air Sampling Results}

Results for full-shift personal air samples for $\mathrm{HCl}$, DGME, and oil mist on one exit operator, and two exit laborers are shown in Table 3. For the exit operator position, the full shift was split between two different employees. Job tasks were the same for both employees, so the sampling results are used as an estimate of typical exposure levels during a full shift on one employee. All personal air sampling results for DGME and oil mist were well below their most protective occupational exposure limits (OELs). Personal air sampling results are fullshift 8-hour TWAs.

Table 3. Personal air sampling results

\begin{tabular}{lcc}
\hline Job title & DGME $(\mathrm{ppm})^{*}$ & Oil mist $\left(\mathrm{mg} / \mathrm{m}^{3}\right) \dagger$ \\
\hline Exit operator & 0.092 & 0.053 \\
Exit laborer 1 & 0.036 & 0.081 \\
Exit laborer 2 & 0.071 & 0.075 \\
\hline NIOSH REL & None & 5 \\
ACGIH TLV§ & 10 & 5 \\
OSHA PEL & None & 5 \\
\hline
\end{tabular}

*Parts per million

†Milligrams per cubic meter

$\ddagger$ This result is from a shift split between two employees

§American Conference of Governmental Industrial Hygienists

(ACGIH) threshold limit value (TLV) 
The OSHA PEL, the NIOSH REL, and the ACGIH TLV for $\mathrm{HCl}$ are ceiling limits that should never be exceeded. These ceiling limits are $5 \mathrm{ppm}$ for the PEL and REL, and $2 \mathrm{ppm}$ for the TLV. Because there is not an 8-hour TWA OEL for $\mathrm{HCl}$, the collected personal sampling results cannot be directly compared to the established OELs mentioned previously. Full-shift personal air sampling results were not detected (minimum detection limit of $0.003 \mathrm{ppm}$ ) for both exit laborers, and $0.021 \mathrm{ppm}$ for the exit operator. The employer reported monitoring $\mathrm{HCl}$ levels once per shift throughout the plant using an $\mathrm{HCl}$ gas detector. These results were not recorded, but the employer reported that no readings have detected $\mathrm{HCl}$.

We also collected full-shift area air samples for $\mathrm{HCl}$ and oil mist on the pickling line and in two crane cabs (Table 4). This was measured to determine levels of contaminants in areas on the line closer to the acid baths and in areas further away from the line. Crane cab operators worked primarily in the crane cabs, only leaving the crane cabs for breaks and to communicate with supervisors during their work shift. Therefore, we used the area air samples to estimate the worst-case exposures of crane cab employees who stayed in the crane for the entire work shift. $\mathrm{HCl}$ and oil mist levels at the quality control area on the pickling line were similar to personal air sample results collected on exit employees in Table 2.

Table 4. Area air sampling results

\begin{tabular}{lcc}
\hline Location & $\mathrm{HCl}(\mathrm{ppm})$ & Oil mist $\left(\mathrm{mg} / \mathrm{m}^{3}\right)$ \\
\hline $\begin{array}{l}\text { Pickling line, } \\
\text { quality control area }\end{array}$ & Not detected & 0.088 \\
$\begin{array}{l}\text { North crane cab } \\
\text { Center crane cab }\end{array}$ & Not detected & Not sampled \\
$\begin{array}{l}{ }^{*} \text { Less than the minimum detectable concentration of } \\
0.003 \text { ppm }\end{array}$ & Not sampled \\
\hline
\end{tabular}

To address concerns of diesel exhaust exposure, we collected full-shift area air samples for elemental carbon in two crane cabs (Table 5). Although these were area air samples, and their results are not directly comparable to OELs, it is helpful to note that the state of California recommends an OEL of $0.02 \mathrm{mg} / \mathrm{m}^{3}$ for elemental carbon. Similar to the air sampling for $\mathrm{HCl}$ and oil mist, we used the area air samples for elemental carbon to estimate the worst-case exposures of crane cab employees who stayed in the crane for the entire work shift.

Table 5. Elemental carbon area air sampling results

\begin{tabular}{lc}
\hline Location & Result $\left(\mathrm{mg} / \mathrm{m}^{3}\right)$ \\
\hline North crane cab & 0.037 \\
Center crane cab & 0.023 \\
Outdoors & 0.0091 \\
\hline
\end{tabular}




\section{Noise}

Full-shift TWA personal dosimetry measurements are shown in Table 6. Noise exposures for one exit laborer and the exit operator exceeded the NIOSH REL of $85 \mathrm{dBA}$ for an 8-hour TWA and the OSHA AL of $85 \mathrm{dBA}$ for an 8-hour TWA. Although the exit laborers had much different full-shift noise exposures, we did not notice a difference in tasks between the two. We observed the laborers working together and alternating tasks in the exit area. Exit area employees were provided with, but were not required to wear hearing protection. We did not observe exit area employees wearing hearing protection, but one exit area employee reported wearing hearing protection intermittently.

Table 6. Full-shift personal noise sampling results

\begin{tabular}{lccc}
\hline Job title & $\begin{array}{c}\text { Result using } \\
\text { NIOSH REL } \\
\text { criterion (dBA) }\end{array}$ & $\begin{array}{c}\text { Results using } \\
\text { OSHA AL } \\
\text { criterion (dBA) }\end{array}$ & $\begin{array}{c}\text { Results using } \\
\text { OSHA PEL } \\
\text { criterion (dBA)* }\end{array}$ \\
\hline Exit laborer 1 & $\mathbf{9 0 . 5}$ & $\mathbf{8 7 . 6}$ & 83.6 \\
Exit laborer 2 & 83.9 & 80.9 & 70.3 \\
Exit operator† & $\mathbf{8 8 . 6}$ & $\mathbf{8 7 . 1}$ & 80.2 \\
\hline Occupational exposure limit & 85 & 85 & 90 \\
(as 8-hour time-weighted averages) & & & \\
\hline
\end{tabular}

${ }^{*}$ The criteria for calculating the OSHA PEL includes all noise exposures greater than or equal to $90 \mathrm{dBA}$.

†This shift was split between two different employees who worked approximately 4 hours each.

Full-shift area noise measurements are shown in Table 7. Because these are not personal sampling results, they cannot be directly compared to the noise exposure limits. However, these results indicate that noise levels were higher in the pickling line entry area than in the crane cabs. Noise exposures of employees working in this area could potentially exceed the NIOSH REL and OSHA AL. We observed one entry laborer continuously wearing hearing protection.

Table 7. Full-shift area noise sampling results

\begin{tabular}{lccc}
\hline Area & $\begin{array}{c}\text { Result using } \\
\text { NIOSH REL criterion } \\
(\text { dBA })\end{array}$ & $\begin{array}{c}\text { Results using } \\
\text { OSHA AL criterion } \\
(\text { dBA })\end{array}$ & $\begin{array}{c}\text { Results using } \\
\text { OSHA PEL criterion } \\
(\text { dBA })\end{array}$ \\
\hline Pickling line entry & 93.3 & 90.3 & 85.8 \\
Center crane cab & 78.9 & 73.3 & 60.4 \\
North crane cab & 76.0 & 70.6 & 50.2 \\
\hline
\end{tabular}


We took short-duration sound level measurements during activities that employees reported as loud (Table 8). These included (1) when the steel coil went through the line entry, (2) threading a new steel coil through the line, (3) when the leading edge of a new coil was cut, and (4) in the tank farm.

Table 8. Short-duration sound level checks

\begin{tabular}{lcc}
\hline Activity/Location & Noise level & Comments \\
\hline $\begin{array}{l}\text { Steel coil passing } \\
\text { through the line entry }\end{array}$ & $104.2-115.4 \mathrm{dBA}$ & $\begin{array}{c}\text { Metal-to-metal contact as the } \\
\text { coil impacted the line }\end{array}$ \\
$\begin{array}{l}\text { Threading a new steel coil } \\
\text { through the line }\end{array}$ & $82.6-91.5 \mathrm{dBA}$ & $\begin{array}{c}\text { Metal-to-metal contact as the pickling line } \\
\text { machinery aligned the coil }\end{array}$ \\
$\begin{array}{l}\text { Cutting a new coil } \\
\text { Tank farm }\end{array}$ & $108.4 \mathrm{dBA}$ & $\begin{array}{l}\text { Noise from metal cutting } \\
\end{array}$ \\
& $95 \mathrm{dBA}$ & $\begin{array}{c}\text { Area where used acid and water was } \\
\text { discarded. Not routinely occupied, } \\
\text { employees entered for maintenance }\end{array}$ \\
\hline
\end{tabular}

\section{Ventilation and Other Controls}

Because of its size (approximately 150,000 square feet), the plant relied mainly on general dilution ventilation. The pickling line had no local exhaust ventilation. The quality wet lab room had two air intakes with supply air recirculated from the plant and no exhaust. The room was positively pressured compared to the plant, meaning that air flowed from the lab to the plant, a desirable ventilation arrangement. However, the $\mathrm{HCl}$ acid solutions were tested on a bench without local exhaust ventilation.

The company had installed two fans near the exit operator station. One fan was on the station platform and blew air away from the station and the exit operator's breathing zone and toward the electrostatic oiler. The other fan was behind and several feet away from the operator station and blew air toward the oiler (Figure 3). The plant also installed an acrylic glass semi-enclosure to contain the oil mist that escaped through the side of the oiler (Figures 3 and 4). This acrylic glass enclosure had visible oil residue on it, indicating that oil escaped through the side openings of the oiler. 


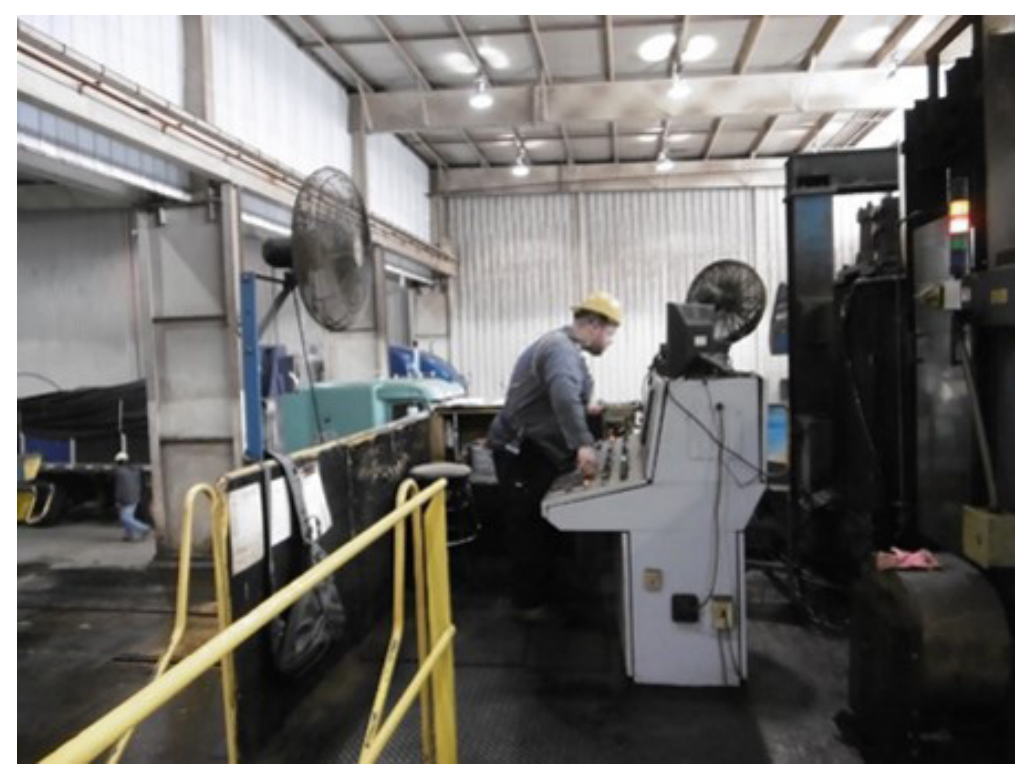

Figure 3. Exit operator at station on left with both installed fans blowing air toward the electrostatic oiler on the right. Photo by NIOSH.

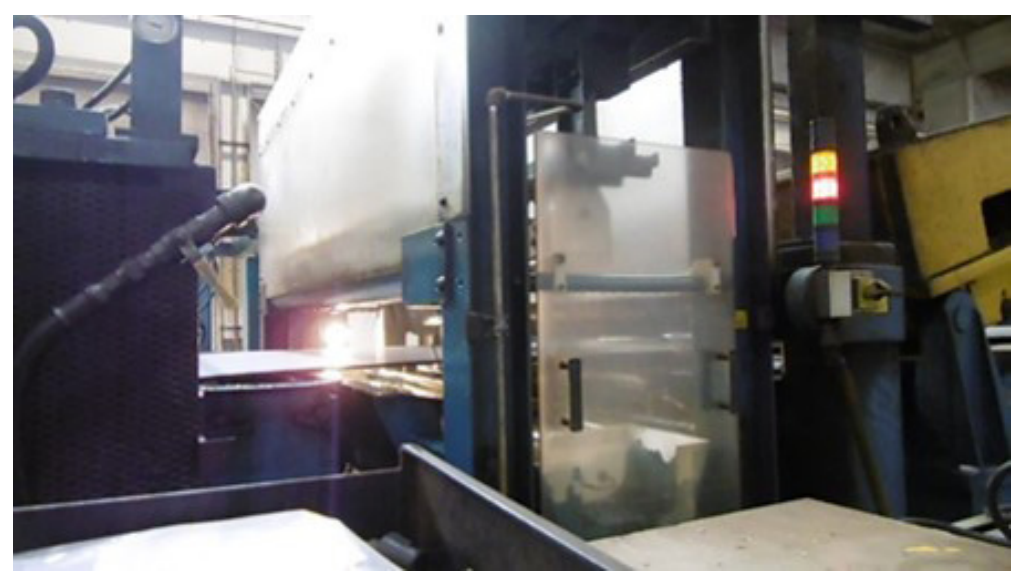

Figure 4. Electrostatic oiler depositing oil onto clean steel coil. The acrylic glass semi-enclosure was installed on the side of the oiler to prevent oil from escaping. Photo by NIOSH.

\section{Confidential Medical Interviews}

We interviewed all 50 employees working across all three shifts during our visit. Their median age was 38 years (range: 21-70 years); 47 (94\%) were male. In total, 21 (42\%) worked first shift; 13 (26\%) worked second shift; 12 (24\%) worked third shift; and four $(8 \%)$ did not specify one particular shift, rotating every few weeks over the three shifts. The median number of hours worked per week was 48 (range: $25-84$ hours). The median duration of work in the plant was 10 years (range: 1 week-40 years). 
Six (12\%) employees reported working primarily in non-production area offices; 44 (88\%) employees reported working primarily in the production area. Of these, $10(23 \%)$ reported working primarily in the exit area, and $6(14 \%)$ reported working primarily in the entry area. Other primary work locations within the production area included the maintenance office, quality office, shipping office, and all over the plant. We classified $9(18 \%)$ employees as supervisors or managers based on their job title. Thirty-three (67\%) employees reported noticing fine oil mists in the air inside the facility. Most of these employees reported noticing them constantly in the exit area and did not specify a seasonal pattern.

We asked employees about their use of PPE while at work. Forty-eight (96\%) employees reported wearing safety glasses at work; 37 reported always wearing them, and 11 reported usually or sometimes wearing them. The two employees who reported not wearing safety glasses were not production employees. Regarding hearing protection, 4 of 10 exit area employees reported wearing earplugs while at work; all reported "sometimes" using them. In addition, five of six entry area employees reported wearing earplugs while at work; three reported "always" using them while two reported "sometimes" using them.

Eleven (22\%) employees reported being current smokers. Five (10\%) employees reported having been diagnosed with asthma. Of these, one reported being diagnosed since working at the plant, and only one reported worsening asthma symptoms since starting work at the plant. Four ( $8 \%$ ) employees reported having been diagnosed with allergies/hay fever, two of whom were diagnosed since working at the plant. None of the employees reported a history of chronic obstructive pulmonary disease. One employee reported having been diagnosed with laryngeal cancer and skin cancer since starting work at the plant.

Table 9 summarizes the symptoms reported by interviewed employees in the previous three months. Employees were asked to exclude symptoms related to colds or upper respiratory infections. In total, $40(80 \%)$ employees reported $\geq 1$ symptom. Thirty-one $(63 \%)$ employees were classified as having work-related irritant symptoms (nasal congestion, sore throat, cough, and/or eye irritation). All worked in the production area for a prevalence of $70.5 \%$ in this area. The most commonly reported work-related symptoms included nasal congestion $(44 \%)$, sore throat $(32 \%)$, and cough $(32 \%)$. 
Table 9. Symptoms reported by interviewed employees in the previous 3 months $(n=50)$

\begin{tabular}{lcc}
\hline Symptom & $\begin{array}{c}\text { No. (\%) employees } \\
\text { reporting symptom }\end{array}$ & $\begin{array}{c}\text { No. (\%) employees reporting } \\
\text { symptom better away from work }\end{array}$ \\
\hline Irritant symptom & $34(68)$ & $31(62)$ \\
Nasal congestion & $25(50)$ & $22(44)$ \\
Sore throat & $19(38)$ & $16(32)$ \\
Cough & $17(34)$ & $16(32)$ \\
Headache & $13(26)$ & $10(20)$ \\
Shortness of breath & $12(24)$ & $10(20)$ \\
Chest tightness or pain & $8(16)$ & $5(8)$ \\
Fatigue & $6(12)$ & $5(10)$ \\
Body aches & $4(8)$ & $2(4)$ \\
Dizziness & $4(8)$ & $4(8)$ \\
Eye irritation* & $4(8)$ & $4(8)$ \\
Rash & $3(6)$ & $2(4)$ \\
Other† & $14(30)$ & $8(16)$ \\
\hline
\end{tabular}

*Only eight employees were asked specifically about eye irritation

†The most common other symptoms reported included heartburn/acid reflux and other nose problems such as dry nose, nosebleeds, and nose sores.

Employees were asked an open-ended question about whether they thought a substance at work could be responsible for their symptoms. Many of the employees with symptoms attributed their symptoms to a variety of things, most commonly dust, oil, acid mists, and diesel exhaust. Of the 40 employees who reported $\geq 1$ symptom, only four $(10 \%)$ reported having taken time off work for the symptoms. In addition, only six (15\%) reported seeing a healthcare provider for any of the symptoms. One employee reported a diagnosis of gastroesophageal reflux disease, one reported a diagnosis of asthma, and one reported a diagnosis of sinusitis. We obtained medical records for the employee who reported a new diagnosis of asthma after 5 years of working at the plant. His spirometry test report concluded that he had possible early obstructive pulmonary impairment. No further testing results were sent to us.

Production area employees were more likely to report work-related irritant symptoms in the previous 3 months compared to office area employees (prevalence ratio: $3.38,95 \%$ confidence interval: 2.14, 5.34). However, among production area employees, employees on the pickling line (i.e., entry and exit area) had a similar prevalence of work-related irritant symptoms compared to employees in other production areas (prevalence ratio: $2.99,95 \%$ confidence interval: $0.43,2.84$ ). Similarly, crane operators had a similar prevalence of workrelated irritant symptoms compared to other production area employees (prevalence ratio: $2.45,95 \%$ confidence interval: $0.40,15.2$ ).

\section{Discussion}

While confidential medical interviews revealed that production area employees were more likely to report work-related irritant symptoms in the previous 3 months compared 
to office area employees, our industrial hygiene assessment was not able to determine the specific causes for these symptoms. Within the production area, it does not appear that specific employee groups, such as those working in the exit area or as crane operators, are disproportionately affected with symptoms. Therefore, it is possible that a number of exposures may have contributed to employees' symptoms including $\mathrm{HCl}$, the oil, diesel exhaust, or environmental allergens such as dust. However, personal and area sampling results only measured the average concentrations that an employee or area was exposed to for a specific contaminant over one full shift during the time that we were at the plant. Therefore, these results may not be generalizable and reflective of exposures at all times. For example, the average time-weighted exposure concentration may be well below the OEL, but instantaneous concentrations may be higher.

We measured low concentrations for $\mathrm{HCl}$, but higher levels of $\mathrm{HCl}$ had been noted by the plant during non-routine tasks such as opening acid baths for maintenance, cleaning acid baths and tanks, or when an $\mathrm{HCl}$ spill occurred. We did not observe any of these scenarios during our site visit; therefore, the sampling we conducted was not representative of $\mathrm{HCl}$ levels during these scenarios. Exposures to $\mathrm{HCl}$ and/or hydrochloric acid can cause respiratory and skin irritation symptoms. Some employees may be sensitive to $\mathrm{HCl}$ exposure even at low concentrations in the air. This might explain some of the irritant symptoms reported among production area employees. Although $\mathrm{HCl}$ concentrations were low or not detectable, we did not take instantaneous measurements of $\mathrm{HCl}$ in the air near the pickling line. There could have been short-term increases in $\mathrm{HCl}$ concentration that were not reflected in a low average concentration over a full 8-hour shift. For example, the concentration for $\mathrm{HCl}$ could have exceeded $2 \mathrm{ppm}$, and the average sampling result still be as low as the results measured.

During our site visit, we noted that surfaces near the electrostatic oiler and exit area, including railings, the floor, and the acrylic glass enclosure were covered with a thin oil film. This shows that the electrostatic oiler did not contain all of the oil as it was being deposited onto the steel. The plant had consulted the manufacturer of the electrostatic oiler about engineering controls and found out that other companies with electrostatic sprayers had not experienced any health complaints from sprayed oil. The manufacturer stated that oil does not leave the oiler when it is correctly operated and maintained, but that oil may escape if the oiler is not using the correct spray width or if the electrostatic oiler is subjected to winds from open doors or fans. The plant stated that they followed maintenance instructions detailed in the manufacturer's manual.

NIOSH recommends reducing personal diesel exhaust exposures to the lowest feasible concentration. Short-term exposure to diesel exhaust has been associated with acute respiratory effects, including irritation of eyes, nose, and throat, and causing cough, headache, lightheadedness, and nausea. Exposure to diesel exhaust can also cause inflammation in the lungs and aggravate chronic respiratory symptoms and asthma [Gamble et al. 1987; Pronk et al. 2009; Reger and Hancock 1980; Sydbom et al. 2001]. Area air sampling for elemental carbon found higher elemental carbon concentrations in the north and center crane cabs compared to outdoor concentrations. The crane cabs are not air-tight, allowing for diesel exhaust from diesel-powered equipment in the area to enter the crane cabs. This might account for some of the work-related symptoms reported among production area employees. In addition, symptoms may have been more prevalent during our visit 
because the garage doors had been closed because of the cold weather. Engineering controls may decrease exposure to diesel exhaust to employees in the crane room storage area.

Tobacco use may also exacerbate symptoms experienced by some employees as over $20 \%$ of interviewed employees were current smokers. Information about health effects associated with chronic exposures to diesel exhaust are in Appendix A.

The employer was also concerned about dust exposure in the storage area and pickling line. There was visible dust throughout the plant, but more in the shipping areas, adjacent to the storage area, where material is moved into and out of the plant. We did not measure dust in the plant air because sampling for non-specific particulate matter in the air is not generally useful in determining sources of work-related irritation and other health symptoms. Additionally, these results would not inform or change our recommendations. Considering the activities and this work environment, we do not expect dust to be present at levels that would be an occupational exposure concern. Nevertheless, dust exposures should be minimized when possible.

Several personal noise exposure measurements on the pickling line exceeded the OSHA AL and/or the NIOSH REL of $85 \mathrm{dBA}$, and area noise measurements in the entry area indicate high noise levels on the line and the potential for overexposure to noise. Many of the line employees did not wear hearing protection while working on the line, and most entry and exit area employees reported during interviews that they only "sometimes" used hearing protection. In addition, hearing protection was not required or included in the plant's PPE policy. The combination of noise exposures exceeding noise exposure limits and lack of hearing protection use increases employees' risk of hearing loss. Engineering controls, such as enclosures for employees and equipment, can also reduce noise exposures. More information about noise in the workplace is in Appendix A.

One employee had an OSHA-recordable standard threshold shift on their most recent audiogram, meaning that they had a change in hearing threshold of an average of $10 \mathrm{~dB}$ or more averaged across $2,000 \mathrm{hertz}(\mathrm{Hz}), 3,000 \mathrm{~Hz}$, and 4,000 Hz, compared to their baseline audiogram. Two other employees were referred due to significant changes in high frequency hearing, or a change of over $20 \mathrm{~dB}$ at $3,000 \mathrm{~Hz}, 4,000 \mathrm{~Hz}$, and 6,000 Hz. We did not review individual audiometric records.

NIOSH considers its criteria for significant threshold shifts to be more protective than the OSHA criteria for a standard threshold shift when reviewing audiograms for hearing loss. The audiometric test provider applied age correction to audiograms, which is permissible by the OSHA noise standard. However, NIOSH does not recommend age correction on audiograms, as this practice is not scientifically valid and could delay intervention to prevent further hearing losses in employees whose hearing threshold levels have increased because of occupational noise exposure [NIOSH 1998]. For example, one employee with a standard threshold shift as defined by OSHA in 2016 had a significant threshold shift as defined by NIOSH in 2009. Intervention to prevent further hearing loss could have been implemented after this identification. 


\section{Conclusions}

We found a high prevalence of reported work-related irritant symptoms among production area employees. Although our industrial hygiene assessment did not determine specific causes for these symptoms, it is possible that a combination of exposures to diesel exhaust and perhaps $\mathrm{HCl}$ and the electrostatically-applied oil, may have contributed to them. While measured exposures for these compounds were low, efforts to further reduce exposures may reduce the prevalence of work-related health concerns. Employees' TWA noise exposures in the exit area exceeded the NIOSH REL and OSHA AL. We also found high noise levels in the pickling line entry area, and one employee with a standard threshold shift indicating noise-induced hearing loss (NIHL). Hearing protection should be required in areas where noise exposures are above the NIOSH REL.

\section{Recommendations}

On the basis of our findings, we recommend the actions listed below. We encourage the plant to use an employer-employee health and safety committee or working group to discuss our recommendations and develop an action plan. Those involved in the work can best set priorities and assess the feasibility of our recommendations for the specific situation at plant.

Our recommendations are based on an approach known as the hierarchy of controls. This approach groups actions by their likely effectiveness in reducing or removing hazards. In most cases, the preferred approach is to eliminate hazardous materials or processes and install engineering controls to reduce exposure or shield employees. Until such controls are in place, or if they are not effective or feasible, administrative measures and PPE may be needed.

\section{Engineering Controls}

Engineering controls reduce employees' exposures by removing the hazard from the process or by placing a barrier between the hazard and the employee. Engineering controls protect employees effectively without placing primary responsibility of implementation on the employee.

1. Replace diesel-powered equipment with non-diesel alternatives.

2. Enclose the crane cabs, provide filtered air to the cabs, and maintain the cabs under positive pressure relative to the surrounding area. These ventilation changes should reduce the amount of diesel exhaust entering the crane cabs.

3. Consult with the electrostatic oiler manufacturer to reduce the amount of oil that escapes from the oiler.

4. Consult with equipment makers when purchasing new equipment or replacing equipment on the pickling line to get equipment that makes the least amount of noise.

5. Consult with a noise control engineer on options to reduce employee's noise exposure. Noise control options include constructing barriers or enclosures around equipment or equipment operators. 


\section{Administrative Controls}

The term administrative controls refers to employer-dictated work practices and policies to reduce or prevent hazardous exposures. Their effectiveness depends on employer commitment and employee acceptance. Regular monitoring and reinforcement are necessary to ensure that policies and procedures are followed consistently.

1. Evaluate audiograms using the NIOSH criteria for identifying significant threshold shifts. The NIOSH criteria are more protective and will provide earlier identification of employees with hearing loss.

2. Request that the audiometric test provider not age correct when evaluating audiograms.

3. Conduct personal noise monitoring on pickling line entry area employees and the quality assurance employee. In addition, conduct personal noise sampling when processes change or new equipment is installed.

4. Instruct employees to promptly report any symptoms possibly related to work and implement a system to track such reports. Encourage employees with work-related health concerns to seek medical care from qualified medical professionals.

5. Increase housekeeping frequency to decrease dust in the plant. Use a vacuum or wet cleaning methods.

6. Encourage employees who smoke to participate in smoking cessation programs. Smoking cessation may decrease symptoms worsened by workplace exposures.

\section{Personal Protective Equipment}

PPE is the least effective means for controlling hazardous exposures. Proper use of PPE requires a comprehensive program and a high level of employee involvement and commitment. The right PPE must be chosen for each hazard. Supporting programs such as training, change-out schedules, and medical assessment may be needed. PPE should not be the sole method for controlling hazardous exposures. Rather, PPE should be used until effective engineering and administrative controls are in place.

1. Require the use of hearing protection for employees who work on the pickling line.

2. Train employees on proper use of hearing protection.

3. Provide employees with a variety of hearing protection to use. These can include different brands and sizes of earplugs or earmuffs.

4. Improve the PPE policy and detail the PPE required for employees by job title or job area. 


\section{Appendix A: Occupational Exposure Limits and Health Effects}

NIOSH investigators refer to mandatory (legally enforceable) and recommended OELs for chemical, physical, and biological agents when evaluating workplace hazards. OELs have been developed by federal agencies and safety and health organizations to prevent adverse health effects from workplace exposures. Generally, OELs suggest levels of exposure that most employees may be exposed to for up to 10 hours per day, 40 hours per week, for a working lifetime, without experiencing adverse health effects. However, not all employees will be protected if their exposures are maintained below these levels. Some may have adverse health effects because of individual susceptibility, a pre-existing medical condition, or a hypersensitivity (allergy). In addition, some hazardous substances act in combination with other exposures, with the general environment, or with medications or personal habits of the employee to produce adverse health effects. Most OELs address airborne exposures, but some substances can be absorbed directly through the skin and mucous membranes.

Most OELs are expressed as a TWA exposure. A TWA refers to the average exposure during a normal 8- to 10-hour workday. Some chemical substances and physical agents have recommended short-term exposure limits or ceiling values. Unless otherwise noted, the shortterm exposure limit is a 15-minute TWA exposure. It should not be exceeded at any time during a workday. The ceiling limit should not be exceeded at any time.

In the United States, OELs have been established by federal agencies, professional organizations, state and local governments, and other entities. Some OELs are legally enforceable limits; others are recommendations.

- The U.S. Department of Labor OSHA PELs (29 CFR 1910 [general industry]; 29 CFR 1926 [construction industry]; and 29 CFR 1917 [maritime industry]) are legal limits. These limits are enforceable in workplaces covered under the Occupational Safety and Health Act of 1970.

- NIOSH RELs are recommendations based on a critical review of the scientific and technical information and the adequacy of methods to identify and control the hazard. NIOSH RELs are published in the NIOSH Pocket Guide to Chemical Hazards [NIOSH 2010]. NIOSH also recommends risk management practices (e.g., engineering controls, safe work practices, employee education/training, PPE, and exposure and medical monitoring) to minimize the risk of exposure and adverse health effects.

- Another set of OELs commonly used and cited in the United States is the ACGIH TLVs. The TLVs are developed by committee members of this professional organization from a review of the published, peer-reviewed literature. TLVs are not consensus standards. They are considered voluntary exposure guidelines for use by industrial hygienists and others trained in this discipline "to assist in the control of health hazards" [ACGIH 2017]. 
Outside the United States, OELs have been established by various agencies and organizations and include legal and recommended limits. The Institut für Arbeitsschutz der Deutschen Gesetzlichen Unfallversicherung (Institute for Occupational Safety and Health of the German Social Accident Insurance) maintains a database of international OELs from European Union member states, Canada (Québec), Japan, Switzerland, and the United States. The database, available at http://www.dguv.de/ifa/GESTIS/GESTIS-Internationale-Grenzwerte-fürchemische-Substanzen-limit-values-for-chemical-agents/index-2.jsp, contains international limits for more than 2,000 hazardous substances and is updated periodically.

OSHA requires an employer to furnish employees a place of employment free from recognized hazards that cause or are likely to cause death or serious physical harm [Occupational Safety and Health Act of 1970 (Public Law 91-596, sec. 5(a)(1))]. This is true in the absence of a specific OEL. It also is important to keep in mind that OELs may not reflect current health-based information.

When multiple OELs exist for a substance or agent, NIOSH investigators generally encourage employers to use the lowest OEL when making risk assessment and risk management decisions. NIOSH investigators also encourage use of the hierarchy of controls approach to eliminate or minimize workplace hazards. This includes, in order of preference, the use of (1) substitution or elimination of the hazardous agent, (2) engineering controls (e.g., local exhaust ventilation, process enclosure, dilution ventilation), (3) administrative controls (e.g., limiting time of exposure, employee training, work practice changes, medical surveillance), and (4) PPE (e.g., respiratory protection, gloves, eye protection, hearing protection). Control banding, a qualitative risk assessment and risk management tool, is a complementary approach to protecting employee health. Control banding focuses on how broad categories of risk should be managed. Information on control banding is available at http://www.cdc.gov/niosh/topics/ctrlbanding/. This approach can be applied in situations where OELs have not been established or can be used to supplement existing OELs.

\section{Noise}

NIHL is an irreversible condition that progresses with noise exposure. It is caused by damage to the nerve cells of the inner ear and, unlike some other types of hearing disorders, cannot be treated medically [Berger et al. 2003]. More than 22 million U.S. employees are estimated to be exposed to workplace noise levels above 85 dBA [Tak et al. 2009]. NIOSH estimates that employees exposed to an average daily noise level of 85 dBA over a 40 -year working lifetime have an $8 \%$ excess risk of material hearing impairment. This excess risk increases to $25 \%$ for an average daily noise exposure of $90 \mathrm{dBA}$ [NIOSH 1998]. NIOSH defines material hearing impairment as an average of the hearing threshold levels for both ears that exceeds $25 \mathrm{~dB}$ at frequencies of $1,000 \mathrm{~Hz}, 2,000 \mathrm{~Hz}, 3,000 \mathrm{~Hz}$, and 4,000 Hz.

Although hearing ability commonly declines with age, exposure to excessive noise can increase the rate of hearing loss. In most cases, NIHL develops slowly from repeated exposure to noise over time, but the progression of hearing loss is typically the greatest during the first several years of noise exposure. NIHL can also result from short-duration exposures to high noise levels or even from a single exposure to an impulse noise or a 
continuous noise, depending on the intensity of the noise and the individual's susceptibility to NIHL [Berger et al. 2003]. Noise-exposed employees can develop substantial NIHL before it is clearly recognized. Even mild hearing losses can impair a person's ability to understand speech and hear many important sounds. In addition, some people with NIHL also develop tinnitus. Tinnitus is a condition in which a person perceives sound in one or both ears, but no external sound is present. Persons with tinnitus often describe hearing ringing, hissing, buzzing, whistling, clicking, or chirping like crickets. Tinnitus can be intermittent or continuous and the perceived volume can range from soft to loud. Currently, there is no cure for tinnitus.

The preferred unit for reporting of noise measurements is the dBA. A-weighting is used because it approximates the "equal loudness perception characteristics of human hearing for pure tones relative to a reference of $40 \mathrm{~dB}$ at a frequency of $1,000 \mathrm{~Hz}$ " and is considered to provide a better estimation of hearing loss risk than using unweighted or other weighting measurements [Berger 2003].

Employees exposed to noise should have baseline and yearly hearing tests to evaluate their hearing thresholds and determine whether their hearing has changed over time. Hearing testing should be done in a quiet location, such as an audiometric test booth where background noise does not interfere with accurate measurement of hearing thresholds. In workplace hearing conservation programs, hearing thresholds must be measured at $500 \mathrm{~Hz}$, $1,000 \mathrm{~Hz}, 2,000 \mathrm{~Hz}, 3,000 \mathrm{~Hz}, 4,000 \mathrm{~Hz}$, and 6,000 Hz. Additionally, NIOSH recommends testing at $8,000 \mathrm{~Hz}$ [NIOSH 1998]. The OSHA hearing conservation standard requires analysis of changes from baseline hearing thresholds to determine if the changes are substantial enough to meet OSHA criteria for a standard threshold shift. OSHA defines a standard threshold shift as a change in hearing threshold (relative to the baseline hearing test) of an average of $10 \mathrm{~dB}$ or more at $2,000 \mathrm{~Hz}, 3,000 \mathrm{~Hz}$, and 4,000 Hz in either ear [29 CFR 1910.95]. If a standard threshold shift occurs, the company must determine if the hearing loss also meets the requirements to be recorded on the OSHA Logs [29 CFR 1904.1]. In contrast to OSHA, NIOSH defines a significant threshold shift as a change in the hearing threshold level of $15 \mathrm{~dB}$ or more (relative to the baseline hearing test) at any test frequency in either ear measured twice in succession [NIOSH 1998].

NIOSH has an REL for noise of $85 \mathrm{dBA}$, as an 8-hour TWA. For calculating exposure limits, NIOSH uses a 3-dB time/intensity trading relationship, or exchange rate. Using the NIOSH criterion, an employee can be exposed to $88 \mathrm{dBA}$ for no more than 4 hours, $91 \mathrm{dBA}$ for 2 hours, $94 \mathrm{dBA}$ for 1 hour, $97 \mathrm{dBA}$ for 0.5 hours, etc. Exposure to impulsive noise should never exceed $140 \mathrm{dBA}$. For extended work shifts NIOSH adjusts the REL to $84.5 \mathrm{dBA}$ for a 9-hour shift, 84.0 dBA for a 10-hour shift, 83.6 dBA for an 11-hour shift, and 83.2 dBA for a 12 -hour work shift. NIOSH recommends the use of hearing protection and implementation of a hearing loss prevention program when noise exposures exceed the REL [NIOSH 1998].

The OSHA noise standard specifies a PEL of $90 \mathrm{dBA}$ and an AL of $85 \mathrm{dBA}$, both as 8-hour TWAs. OSHA uses a less conservative 5-dB exchange rate for calculating the PEL and AL. Using the OSHA criterion, an employee may be exposed to noise levels of $95 \mathrm{dBA}$ for no more than 4 hours, $100 \mathrm{dBA}$ for 2 hours, $105 \mathrm{dBA}$ for 1 hour, $110 \mathrm{dBA}$ for 0.5 hours, etc. Exposure to impulsive or impact noise must not exceed $140 \mathrm{~dB}$ peak noise level. OSHA does 
not adjust the PEL for extended work shifts. However, the AL is adjusted to $84.1 \mathrm{dBA}$ for a 9-hour shift, $83.4 \mathrm{dBA}$ for a 10-hour shift, $82.7 \mathrm{dBA}$ for an 11-hour shift, and $82.1 \mathrm{dBA}$ for a 12-hour work shift. OSHA requires implementation of a hearing conservation program when noise exposures exceed the AL [29 CFR 1910.95].

\section{Diethylene Glycol Monobutyl Ether}

DGME is primarily used as a solvent for dyes, soaps, and oils. Routes of exposure for employees who use products containing DGME include inhalation and direct skin contact. Short-term exposure to DGME can cause eye irritation. Exposure to skin can result in dry skin and exposure to eyes can cause pain and redness [International Labour Organization and World Health Organization 2017]. One human case study reported allergic contact dermatitis from exposure to DGME [Berlin et al. 1995]. OSHA and NIOSH have not established an OEL for DGME. The ACGIH TLV is $10 \mathrm{ppm}$ as an 8-hour TWA.

\section{Hydrogen Chloride}

$\mathrm{HCl}$, the aqueous form of hydrochloric acid, is irritating and corrosive to any tissue it contacts. Brief inhalation exposure to low concentrations can cause throat irritation. Longterm exposures to low levels can cause respiratory problems, eye and skin irritation, and discoloration of the teeth. Exposure to higher concentrations than those measured during this evaluation can result in rapid breathing, narrowing of the bronchioles (airways) in the lungs, and accumulation of fluid in the lungs. Some individuals may develop an inflammatory reaction to $\mathrm{HCl}$ [ATSDR 2015]. This condition is called reactive airways dysfunction, a type of asthma caused by some irritating or corrosive substances.

The Department of Health and Human Services, the International Agency for Research on Cancer, and the Environmental Protection Agency have not classified $\mathrm{HCl}$ as to its carcinogenicity. The International Agency for Research on Cancer considers $\mathrm{HCl}$ to not be classifiable as to its carcinogenicity to humans. A mortality study demonstrated an excess lung cancer risk among employees exposed to acids other than sulfuric acid, but causality has not been proven [Beaumont et al. 1987].

The NIOSH REL and OSHA PEL for $\mathrm{HCl}$ is a ceiling limit, or a limit that should never be exceeded, of $5 \mathrm{ppm}$. The ACGIH TLV for $\mathrm{HCl}$ is a ceiling limit of $2 \mathrm{ppm}$. NIOSH, OSHA, and ACGIH do not have full-shift TWA OELs for $\mathrm{HCl}$.

\section{Diesel Exhaust}

Diesel exhaust is a complex mixture of various gases and fine particles. Diesel exhaust is typically black in color with a low odor threshold (odors easily detected at low concentrations) and contains more than 40 toxic compounds [EPA 2002]. The gases in diesel exhaust include hydrocarbons and oxides of carbon, sulfur, and nitrogen [NIOSH 1988; OSHA 1988]. The particles mainly consist of organic carbon compounds adsorbed onto cores of microscopic elemental carbon. More than $95 \%$ of these particles are less than 1 micrometer in size and are respirable [NIOSH 2016]. Because of their small size, diesel exhaust particles can be inhaled deeply into the lungs and even into the bloodstream. 
Exposure to diesel exhaust has been associated with acute and chronic respiratory effects and lung cancer [EPA 2002]. Diesel exhaust exposure is associated with acute health effects, such as eye, nose, throat, and lung irritation; cough; headache; lightheadedness; and nausea [Gamble et al. 1987; Pronk et al. 2009; Reger and Hancock 1980; Sydbom et al. 2001]. Diesel exhaust exposure is also associated with lung inflammation, and can aggravate asthma and other chronic respiratory conditions, and make allergenic responses worse [Sydbom et al. 2001; Ulfvarson and Alexandersson 1990]. Whether a person experiences these acute or chronic health effects depends on the duration and magnitude of the exposures and on individual susceptibility.

Research from NIOSH has shown an increased risk of death from lung cancer in underground miners [Attfield et al. 2012]. The International Agency for Research on Cancer has concluded, with sufficient evidence, that diesel exhaust is a Group 1 human carcinogen that causes lung cancer, and is positively associated, with limited evidence, with an increased risk of bladder cancer [IARC 2012]. NIOSH considers diesel exhaust emissions a potential occupational carcinogen and recommends exposure be kept at the lowest feasible concentration. NIOSH is currently developing quantitative RELs based on human and/or animal data, with consideration to the availability of workplace exposure controls. OSHA does not have a PEL for diesel exhaust. In 2002, the California Department of Public Health recommended a $20 \mu \mathrm{g} / \mathrm{m}^{3}$ OEL for diesel exhaust (as elemental carbon) [CDPH 2002]. 


\section{References}

ACGIH [2017]. 2017 TLVs ${ }^{\circledR}$ and BEIs ${ }^{\circledR}:$ threshold limit values for chemical substances and physical agents and biological exposure indices. Cincinnati, OH: American Conference of Governmental Industrial Hygienists.

ATSDR [2015]. ATSDR ToxFAQs for hydrogen chloride. Atlanta, GA: U.S. Department of Health and Human Services, Agency for Toxic Substances and Disease Registry. https://www.atsdr.cdc.gov/toxfaqs/tf.asp?id=759\&tid=147.

Attfield MD, Schleiff PL, Lubin JH, Blair A, Stewart PA, Vermeulen R, Coble JB, Silverman DT [2012]. The diesel exhaust in miners study: a cohort mortality study with emphasis on lung cancer. J Natl Cancer Inst 104(11):869-883, http://dx.doi.org/10.1093/jnci/djs035.

Beaumont JJ, Leveton J, Knox K, Bloom T, McQuiston T, Young M, Goldsmith R, Steenland NK, Brown DP, Halperin WE [1987]. Lung cancer mortality in workers exposed to sulfuric acid mist and other acid mists. J Natl Cancer Inst 79(5):911-921, https://doi.org/10.1093/jnci/79.5.911.

Berger EH, Royster LH, Royster JD, Driscoll DP, Layne M, eds. [2003]. The noise manual. 5th rev. ed. Fairfax, VA: American Industrial Hygiene Association.

Berlin K, Johanson G, Lindberg M [1995]. Hypersensitivity to 2-(2-butoxyethoxy)ethanol. Contact Dermatitis 32(1):54, https://doi.org/10.1111/j.1600-0536.1995.tb00849.x.

CDPH [2002]. Health hazard advisory: diesel engine exhaust. Oakland, California: Hazard Evaluation System and Information Service, California Department of Health Services (CDHS), Occupational Health Branch, http://www.cdph.ca.gov/programs/hesis/Documents/diesel.pdf.

CFR. Code of Federal Regulations. Washington, DC: U.S. Government Printing Office, Office of the Federal Register.

Environmental Protection Agency [2002]. Health assessment document for diesel engine exhaust. Washington, DC: National Center for Environmental Assessment, Office of Transportation and Air Quality, U.S. Environmental Protection Agency Publication No. EPA/600/8-90/057F.

Gamble J, Jones W, Mishall S [1987]. Epidemiological-environmental study of diesel bus garage workers: acute effects of $\mathrm{NO} 2$ and respirable particulate on the respiratory system. Environ Res 42(1):201-214.

International Agency for Research on Cancer [2012]. IARC: diesel engine exhaust carcinogenic. Lyon, France: World Health Organization, International Agency for Research on Cancer, http://www.iarc.fr/en/media-centre/pr/2012/pdfs/pr213 E.pdf.

International Labour Organization and World Health Organization [2017]. International chemical safety card: 0788 - diethylene glycol monobutyl ether, http://www.ilo.org/dyn/icsc/showcard.display?p_lang=en\&p_card_id=0788\&p_version=2. 
NIOSH [1988]. Current intelligence bulletin 50: carcinogenic effects of exposure to diesel exhaust. Cincinnati, OH: U.S. Department of Health and Human Services, Centers for Disease Control, National Institute for Occupational Safety and Health, DHHS (NIOSH) Publication No. 88-116, https://www.cdc.gov/niosh/docs/88-116/.

NIOSH [1998]. Criteria for a recommended standard: occupational noise exposure (revised criteria 1998). Cincinnati, OH: U.S. Department of Health and Human Services, Centers for Disease Control and Prevention, National Institute for Occupational Safety and Health, DHHS (NIOSH) Publication No. 98-126, http://www.cdc.gov/niosh/docs/98-126/pdfs/98-126.pdf.

NIOSH [2010]. NIOSH pocket guide to chemical hazards. Cincinnati, OH: U.S. Department of Health and Human Services, Centers for Disease Control and Prevention, National Institute for Occupational Safety and Health, DHHS (NIOSH) Publication No. 2010-168c, http://www.cdc.gov/niosh/npg/.

NIOSH [2017]. NIOSH manual of analytical methods (NMAM). 5th ed. O'Connor PF, Ashley K, eds. Cincinnati, OH: U.S. Department of Health and Human Services, Centers for Disease Control and Prevention, National Institute for Occupational Safety and Health, DHHS (NIOSH) Publication No. 2014-151, http://www.cdc.gov/niosh/nmam.

OSHA [1988]. Hazard information bulletin on potential carcinogenicity of diesel exhaust. Washington, DC, U.S. Department of Labor, Occupational Safety and Health Administration. OSHA Bulletin 19881130.

Pronk A, Coble J, Stewart PA [2009]. Occupational exposure to diesel engine exhaust: a literature review. J Expo Sci Environ Epidemiol 19(5):443-457, http://dx.doi.org/10.1038/jes.2009.21.

Reger R, Hancock J [1980]. Coal miners exposed to diesel exhaust emissions. In: Rom W, Archer V, eds. Health implications of new energy technologies. Ann Arbor, MI: Ann Arbor Science Publishers, Inc., pp. 212-231.

Sydbom A, Blomberg A, Parnia S, Stenfors N, Sandström T, Dahlén SE [2001]. Health effects of diesel exhaust emissions. Eur Respir J 17(4):733-746.

Tak S, Davis RR, Calvert GM [2009]. Exposure to hazardous workplace noise and use of hearing protection devices among U.S. workers-NHANES, 1999-2004. Am J Ind Med 52(5):358-371, http://dx.doi.org/10.1002/ajim.20690.

Ulfvarson U, Alexandersson R [1990]. Reduction in adverse effect on pulmonary function after exposure to filtered diesel exhaust. Am J Ind Med 17(3):341-347, http://dx.doi.org/10.1002/ajim.4700170306. 
Keywords: North American Industry Classification System (NAICS) 331110 (Iron and Steel Mills and Ferroalloy Manufacturing); Indiana; Steel Coil, Steel Pickling, Hydrochloric Acid, Hydrogen Chloride, Oil Mist, Electrostatically-Applied Oil, Electrostatic Application, Diesel Exhaust, Noise, Irritant Symptoms 
The Health Hazard Evaluation Program investigates possible health hazards in the workplace under the authority of the Occupational Safety and Health Act of 1970 (29 U.S.C. § 669(a) (6)). The Health Hazard Evaluation Program also provides, upon request, technical assistance to federal, state, and local agencies to investigate occupational health hazards and to prevent occupational disease or injury. Regulations guiding the Program can be found in Title 42, Code of Federal Regulations, Part 85; Requests for Health Hazard Evaluations (42 CFR Part 85).

\section{Disclaimer}

The recommendations in this report are made on the basis of the findings at the workplace evaluated and may not be applicable to other workplaces.

Mention of any company or product in this report does not constitute endorsement by NIOSH.

Citations to Web sites external to NIOSH do not constitute NIOSH endorsement of the sponsoring organizations or their programs or products. NIOSH is not responsible for the content of these Web sites. All Web addresses referenced in this document were accessible as of the publication date.

\section{Acknowledgments}

Analytical Support: Maxxam Analytics

Desktop Publisher: Shawna Watts

Editor: Ellen Galloway

Logistics: Donnie Booher, Kevin Moore

Medical Field Assistance: Shilpa Gowda, Sangeeta Kaushik (medical rotator)

\section{Availability of Report}

Copies of this report have been sent to the employer and employees at the facility. The state and local health department and the Occupational Safety and Health Administration Regional Office have also received a copy. This report is not copyrighted and may be freely reproduced.

\section{Recommended citation for this report:}

NIOSH [2018]. Evaluation of exposures in a steel coil pickling plant. By Li JF, de Perio MA. Cincinnati, OH: U.S. Department of Health and Human Services, Centers for Disease Control and Prevention, National Institute for Occupational Safety and Health, Health Hazard Evaluation Report 2017-0022-3311, https://www.cdc.gov/niosh/hhe/reports/pdfs/2017-0022-3311.pdf. 
Delivering on the Nation's promise:

Promoting productive workplaces through safety and health research

To receive NIOSH documents or more information about occupational safety and health topics, please contact NIOSH:

Telephone: 1-800-CDC-INFO (1-800-232-4636)

TTY: 1-888-232-6348

CDC INFO: www.cdc.gov/info

or visit the NIOSH Web site at www.cdc.gov/niosh

For a monthly update on news at $\mathrm{NIOSH}$, subscribe to

$\mathrm{NIOSH}$ eNews by visiting www.cdc.gov/niosh/eNews. 